\title{
A Wideband Slot Antenna with Folded Parasitic Line for Multiple Band Operation
}

\author{
Chatree MAHATTHANAJATUPHAT, Narintra SRISOONTORN, Thanakarn SUANGUN, \\ Prayoot AKKARAEKTHALIN
}

Dept. of Electrical and Computer Engineering, King Mongkut's University of Technology North Bangkok, 1518 Pracharat 1 Rd., Wongsawang, Bangsue, Bangkok, Thailand 10800

cmp@kmutnb.ac.th,ple1975@hotmail.com, s.thanakarn@gmail.com, prayoot@kmutnb.ac.th

Manuscript received March 17, 2016

\begin{abstract}
The rectangular slot antenna with rectangular stub for a wide impedance bandwidth is proposed. In addition, the interference frequency band has been rejected by placing the folded parasitic line surrounding the rectangular stub of the presented antenna. The bidirectional radiation patterns are obtained at all operating frequencies. Also, the average gain of the presented antenna is approximately $3 \mathrm{dBi}$. The antenna properties such as reflection coefficient, radiation patterns and gains are evaluated via numerical simulation and measurement. The presented antenna can support the multiple band operation at frequency bands of 824-960 MHz and 1710-2485 $\mathrm{MHz}$.
\end{abstract}

\section{Keywords}

Wideband, slot antenna, parasitic line, notched frequency

\section{Introduction}

Nowadays, wireless communication systems, which use antennas to radiate or receive electromagnetic waves, have been grown very fast wherever in mobile communications, warehouse manufacturing systems, industrial communications, medical services, and etc. [1-4]. Also, many wireless communication systems require antennas responding to multiband operation with low profile. However, multiband antennas could be designed by using either multi-resonators or wideband notch technique to produce multiple band operation [5-8].

In literature review, the antenna with multiple resonators was proposed consisting of a two-strip monopole and a meandered strip line for responding to low and high resonant frequencies, respectively [9]. Next, the antenna using parasitic element was designed to perform three resonant modes [10]. This antenna includes the L-shape stub acting as the transmission line, and a U-shape stub for responding to the first and second resonance frequencies. Also, the third resonant frequency of the antenna was occurred due to the slot of the U-shape stub. Especially, the multiband antenna composing of the monopole strip line connecting to the bow-tie patch to radiate at the first and third resonant frequencies, respectively, and the parasitic loop placed on the bottom layer responding to the second resonant frequency was presented in [11]. As the previous reviews, the multiband antennas designed by using multiple resonator technique can radiate independently electromagnetic field at each resonant frequency. However, it is very difficult for designing this type of antenna because the electromagnetic coupling between resonators affects to the impedance bandwidth.

Moreover, multiband antennas could be produced by creating the conventional wideband antennas with frequency band notches. This technique can be helpful to reduce the filter circuit components used to filter out the undesired interference frequencies in the mobile communication system. In [12], the multiband antenna was proposed by creating the wideband antenna with step impedance resonator (SIR). The SIR was built on the CPW-fed transmission line for rejecting unwanted frequency of X-band by tuning an embedded inner stub. However, it can be found that the antenna has the limited area on transmission line to design the frequency band notch, resulting in laborious design on transmission line at low frequency band. In [13], the wideband antenna consisting of a circular patch to produce the wideband frequency operation was proposed. The U-shape slot was inserted in the circular patch to reject the WLAN frequency band. Also, the wideband antenna with complementary split-ring resonators in the T-stub was presented in [14]. As the previous reviews in [13], [14], it can be noticed that it was difficult to design the frequency band notch at the low frequency band because of the limited space in the region of either the patch or stub. Therefore, in order to eliminate the limitation of low frequency band notch design, the ultra wideband slot antenna with a parasitic element for notching frequency band was proposed in [15]. The antenna composes of the circular slot, circular patch, and C-shaped parasitic strip. The C-shaped parasitic placed inside the circular slot is used to reject the undesired frequency band. Also, the ultra-wideband slot antenna with parasitic open-circuit stub was presented 
in [16]. It has been found that the notched frequency band can be varied by adjusting the open-circuit stub. However, both presented antennas in [15], [16] have very narrow band notches and it is very difficult to create the band notches at low frequency due to limited spaces for parasitic elements. Therefore, this technique may not be suitable to use for multiple band operation in some modern wireless communication systems. To overcome this problem, a new folded step parasitic line is proposed to be used with a conventional wideband slot antenna in this paper. By using this technique, not only the notched band at lower frequency can be obtained but also the impedance bandwidth can be easily adjusted.

The proposed antenna consists of a rectangular slot with a rectangular stub to generate the wideband operation. Coupled electromagnetic fields between the antenna and the folded step parasitic line will create a notched frequency. Furthermore, the notched frequency band can be independently adjusted even at the low frequency due to there is no area limitation of antenna slot. Especially, the proposed antenna can cover the operating frequency bands of GSM 850 (Global System for Mobile communication) (824-894 MHz), GSM 900 (890-960 MHz), DCS 1800 (Digital Communication System) (1710-1880 MHz), PCS 1900 (Personal Communication System) (1850 to $1990 \mathrm{MHz}$ ), UMTS 2100 (Universal Mobile Telecommunication System) (1920-2170 MHz), and WLAN IEEE $802.11 \mathrm{~b} / \mathrm{g}$ (Wireless Local Area Network) (2400 to $2484 \mathrm{MHz}$ ). The significant parameters of the proposed antenna will be investigated by using the CST microwave studio software. The presented antenna prototype will be determined and experimented.

The organization of the paper consists of antenna design in Sec 2. Then, parameter study will be performed in Sec. 3. Also, simulation and experiment of antenna characteristics will be verified in Sec. 4. Finally, results and conclusions of the presented antenna are given in Sec. 5 .

\section{Antenna Design}

Figure 1(a) illustrates the configuration of the presented antenna with folded parasitic line. It composes of a rectangular slot and a rectangular patch stub to perform wideband operation. In addition, the folded parasitic line, as depicted in Fig. 1(b), is placed on the surrounding of the rectangular patch stub to create a notched band for preventing unwanted frequency. Also, the rectangular patch stub is excited by connecting with the $50 \Omega$ microstrip line $\left(W_{\mathrm{f}}=3 \mathrm{~mm}\right)$ fed by the SMA connector. The presented antenna is designed on the substrate of FR-4 with the thickness $h$ of $1.6 \mathrm{~mm}$ and the relative permittivity $\varepsilon_{\mathrm{r}}$ of 4.1.

Therefore, the rectangular patch stub is evaluated and optimized to cover the high frequency of the wideband antenna, which has the dimension $\left(L_{\mathrm{t}} \times W_{\mathrm{t}}\right)$ of $30.5 \times 47 \mathrm{~mm}^{2}$. Moreover, the rectangular slot with the dimension of
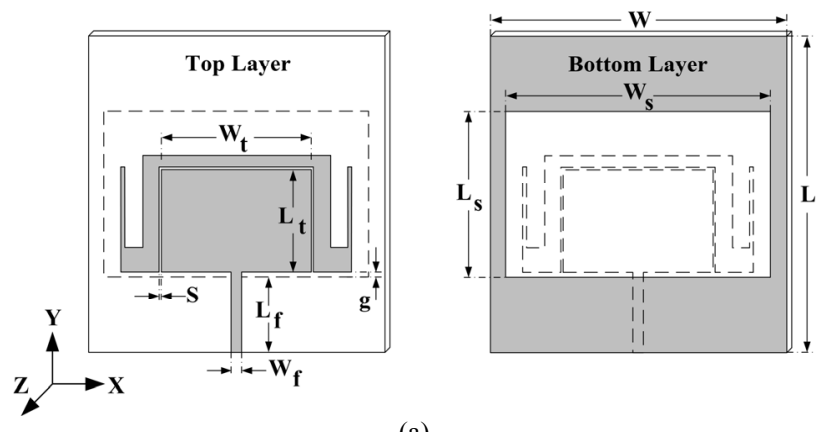

(a)

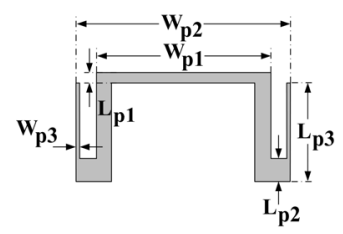

(b)

Fig. 1. Antenna configuration of (a) top and bottom layers and (b) folded parasitic line.

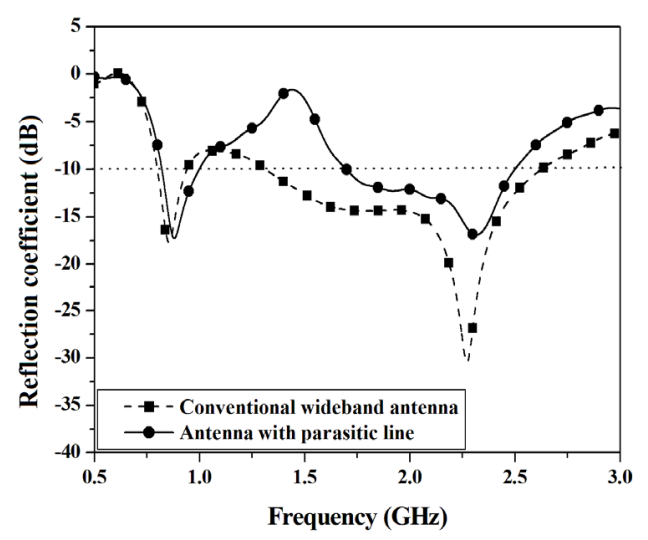

Fig. 2. Simulated reflection coefficients of the wideband slot antennas with and without folded parasitic line.

$\left(W_{\mathrm{s}} \times L_{\mathrm{s}}\right) 75.5 \times 49 \mathrm{~mm}^{2}$ is determined to reinforce the low and high frequencies of the wideband antenna. As the results, the conventional wideband slot antenna can be created. Consequently, the convention wideband slot antenna will be combined with the folded parasitic line to create the undesired frequency rejection band as the result depicted in Fig. 2. It can be clearly seen that the wideband antenna with the folded parasitic line has lower reflection coefficient level than the wideband antenna without it at the resonant frequency of $1.44 \mathrm{GHz}$, as a notched frequency. The simulated notch bandwitdth is about $700 \mathrm{MHz}$ (from $977 \mathrm{MHz}$ to $1.7 \mathrm{GHz}$ ) caused by the step impedance of the folded parasitic line. Due to its low impedance, the folded parasitic line absorbs a large amount of current distribution to create a wideband notch at the resonant frequency of $1.44 \mathrm{GHz}$. However, it is not either disturbed or slightly disturbed total radiation impedance of the antenna at ranges of 824-960 MHz and 1710-2485 MHz.

In order to investigate antenna parameter affecting to the notched frequency and impedance bandwidth, the significant parameters of $L_{\mathrm{P} 3}, W_{\mathrm{s}}$, and $g$ of the presented antenna will be explored in next section. 


\section{Parametric Study}

This section presents the investigation of significant parameters to comprehend behaviors of the proposed antenna and evaluate the optimum values. Before investigating the significant parameters of $L_{\mathrm{P} 3}, W_{\mathrm{s}}$, and $g$ to understand and observe the antenna behavior such as a notched frequency, resonant frequency, and impedance bandwidth, the optimum parameters of the presented antenna have been fixed as following: $W_{\mathrm{p} 1}=57.5 \mathrm{~mm}, W_{\mathrm{p} 2}=69.5 \mathrm{~mm}$, $W_{\mathrm{p} 3}=1 \mathrm{~mm}, W_{\mathrm{t}}=47 \mathrm{~mm}, W_{\mathrm{f}}=3 \mathrm{~mm}, W=84.5 \mathrm{~mm}$, $L_{\mathrm{p} 1}=3 \mathrm{~mm}, L_{\mathrm{p} 2}=7 \mathrm{~mm}, L_{\mathrm{t}}=30.5 \mathrm{~mm}, L_{\mathrm{f}}=21.5 \mathrm{~mm}$, $L_{\mathrm{s}}=49 \mathrm{~mm}, L=92 \mathrm{~mm}, S=0.5 \mathrm{~mm}$.

In order to investigate the notched frequency response, the significant parameters of $W_{\mathrm{s}}=75.5 \mathrm{~mm}$, $g=1.5 \mathrm{~mm}$ should be initiated. Also, the parameter $L_{\mathrm{P} 3}$ has been altered to $27 \mathrm{~mm}, 31 \mathrm{~mm}$, and $35 \mathrm{~mm}$, respectively, to observe the effect of notched frequency, as results illustrated in Fig. 3. When increasing the value of parameter $L_{\mathrm{P} 3}$ as depicted in Fig. 3, it has been clearly found that the notched frequency shifts to the lower frequency because the electrical length of the folded parasitic line is extended. Moreover, the lower cut off frequency of the second band shifts to the lower frequency and impedance bandwidth widens because the extending of the parameter $L_{\mathrm{P} 3}$ is close to the upper ground side of the bottom layer, resulting in the electromagnetic coupling effect between them. However, the parameter $L_{\mathrm{P} 3}=31 \mathrm{~mm}$ should be selected to avoid the interference frequency and remain for supporting sufficient operating frequency band of 1710 to $2485 \mathrm{MHz}$.

Additionally, the resonant frequency will be investigated by varying the parameter $W_{\mathrm{s}}$. In Fig. 4 , it could be obviously seen that the first resonant frequency shifts to the lower frequency, as increasing the parameter $W_{\mathrm{s}}=$ $71.5 \mathrm{~mm}, 75.5 \mathrm{~mm}$, and $79.5 \mathrm{~mm}$ while the parameters of $L_{\mathrm{P} 3}=31$ and $g=1.5 \mathrm{~mm}$ are fixed, due to the increasing electrical length of the inner slot of the presented antenna, resulting in the narrow impedance bandwidth in the second resonant frequency band. Especially, the optimum value of parameter $W_{\mathrm{s}}=75.5 \mathrm{~mm}$ has been chosen to create the pre sented antenna covering the operating frequency bands of 824-960 MHz and 1710-2485 MHz. Furthermore, as the parameters of $L_{\mathrm{P} 3}=31 \mathrm{~mm}$ and $W_{\mathrm{s}}=75.5 \mathrm{~mm}$ fixed, the impedance bandwidth of the presented antenna could be observed by varying the parameter of $g=0 \mathrm{~mm}, 1.5 \mathrm{~mm}$, and $3 \mathrm{~mm}$, respectively. As the results illustrated in Fig. 5, it has been noticed that the upper frequency of the first frequency band shifts to the higher frequency and the impedance bandwidth is improved as increasing the parameter $g=0 \mathrm{~mm}, 1.5 \mathrm{~mm}$, and $3 \mathrm{~mm}$, respectively because of the matching impedance of the antenna closed to $50 \mathrm{ohm}$ at the operating frequency band. However, the parameter $g=1.5 \mathrm{~mm}$ is suitable to obtain the desired operating frequency bands of $824-960 \mathrm{MHz}$ and $1710-2485 \mathrm{MHz}$. Therefore, the optimum parameter values of $L_{\mathrm{P} 3}=31 \mathrm{~mm}$, $W_{\mathrm{s}}=75.5 \mathrm{~mm}$, and $\mathrm{g}=1.5 \mathrm{~mm}$ are obtained and used to fabricate the presented antenna.

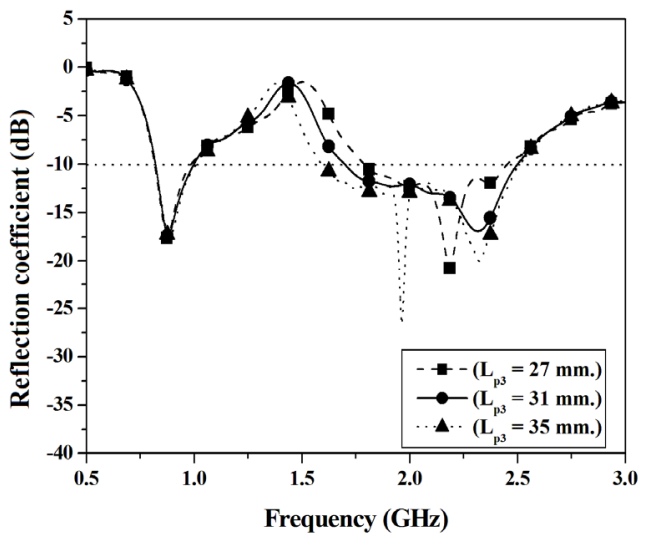

Fig. 3. Simulated reflection coefficients of the presented antenna as varied $L_{\mathrm{p} 3}=27 \mathrm{~mm}, 31 \mathrm{~mm}$, and $35 \mathrm{~mm}$.

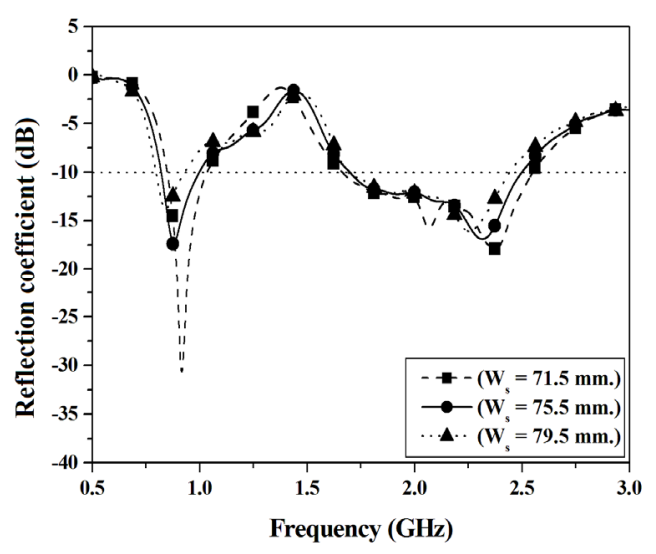

Fig. 4. Simulated reflection coefficients of the presented antenna as varied $W_{\mathrm{s}}=71.5 \mathrm{~mm}, 75.5 \mathrm{~mm}$, and $79.5 \mathrm{~mm}$.

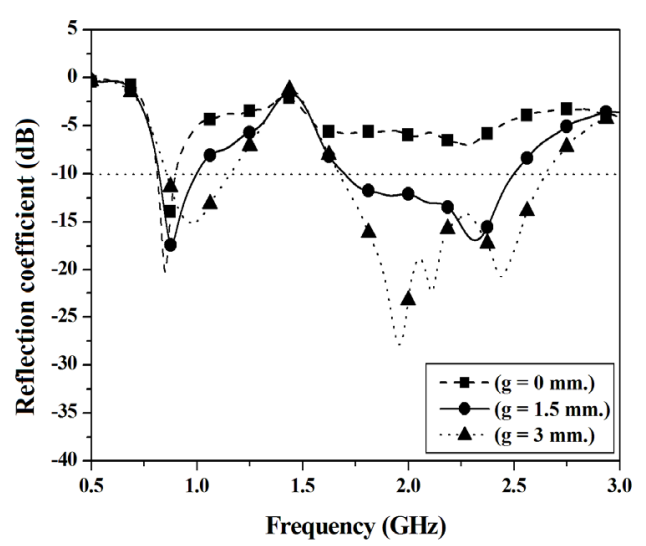

Fig. 5. Simulated reflection coefficients of the presented antenna as varied $g=0 \mathrm{~mm}, 1.5 \mathrm{~mm}$, and $3 \mathrm{~mm}$.

\section{Results and Discussion}

In this section, the presented antenna is fabricated on the FR4 substrate with the dimension of $(W \times L)$ $84.5 \times 92 \mathrm{~mm}^{2}$ etched by milling machine as the prototype antenna shown in Fig. 6. Therefore, the simulated and measured reflection coefficients of the presented antenna are compared as shown in Fig. 7. It can be clearly found that the simulated and measured results agree very well 
covering the operating frequency bands of $824-960 \mathrm{MHz}$ and $1710-2485 \mathrm{MHz}$.

Additionally, the simulated current distribution will be investigated to verify the antenna mechanism as shown in Fig. 8. At the frequency of $900 \mathrm{MHz}$, the major current distribution flows through the outer edge of the slot on metallic ground at the antenna bottom layer, which has the electrical length about $1 \lambda_{0}$, as depicted in Fig. 8(a). It has been noticed that the outer edge of slot responses to the first frequency band of $824-960 \mathrm{MHz}$. As the results shown in Fig. 8(b), it can be clearly seen that the main current distribution is occurred on the rectangular stub edge to propagate the electromagnetic filed at inner slot, which it has the electrical length about $1 \lambda_{0}$ at the operating frequency of $1800 \mathrm{MHz}$. Moreover, the simulated current distribution is evaluated at the operating frequency of $2450 \mathrm{MHz}$ as illustrated in Fig. 8(c). It has been found that the current distribution flows on the upper edge region of the rectangular stub. This results in tilting the electromagnetic field radiation of the main beam at the angle of 330 degree and 210 degree in YZ-plane at the operating frequency of $2450 \mathrm{MHz}$. Especially, the notched frequency of the antenna can be verified by current distribution on the folded parasitic line as shown in Fig. 8(d). As the result, it has been noticed that the major current distribution flows on the folded parasitic line at the notched frequency of $1437 \mathrm{MHz}$. The folded parasitic line performs as a load to absorb the electromagnetic field, which the result can be considered with the antenna gain as illustrated in Fig. 9. However, in the measured result, the lowest gain is slightly shifted from $1437 \mathrm{MHz}$ to the higher frequency due to a little antenna fabrication error. It has been indicated that the antenna gain responds to the operating frequency bands of $824-960 \mathrm{MHz}$ and $1710-2485 \mathrm{MHz}$ and the gain is eliminated at the notched frequency of $1437 \mathrm{MHz}$ consistent with the current distribution flowing in Fig. 8(d). However, the antenna average gain is approximately $3 \mathrm{dBi}$ at the angle of 0 degree at the operating frequencies. The measured radiation patterns of the presented antenna at all operating frequencies are depicted in Fig. 10. It has been clearly found that the cross polarization patterns expand when the frequency is higher than $1800 \mathrm{MHz}$. This is due to the current distribution flowing through the rectangular

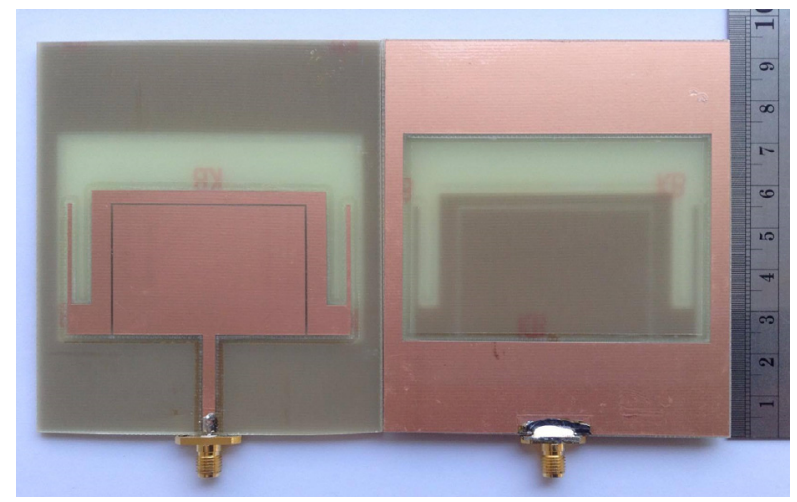

Fig. 6. Prototype of the fabricated slot antenna with folded parasitic line.

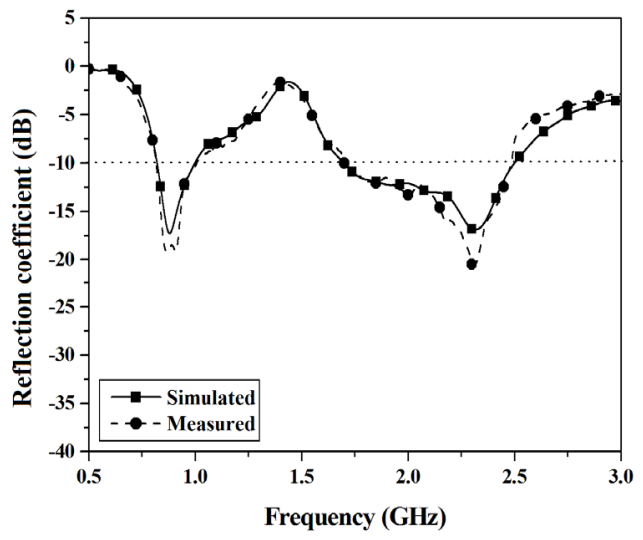

Fig. 7. Simulated and measured reflection coefficients of the presented antenna.

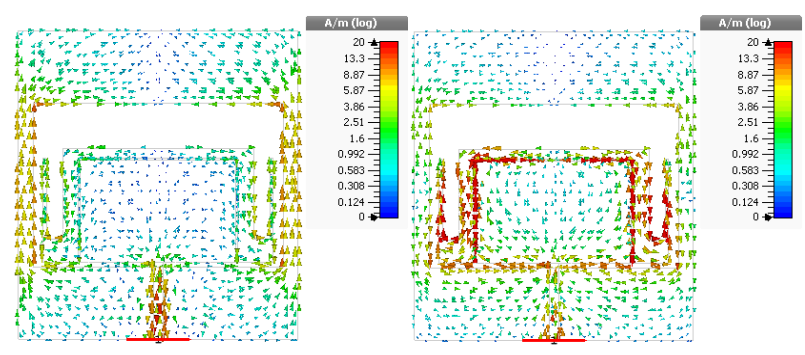

(a)

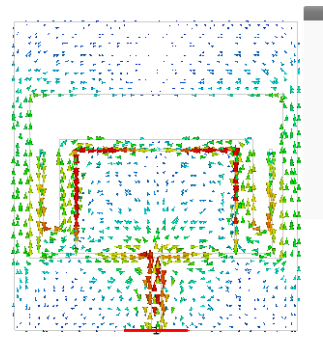

(c) (b)

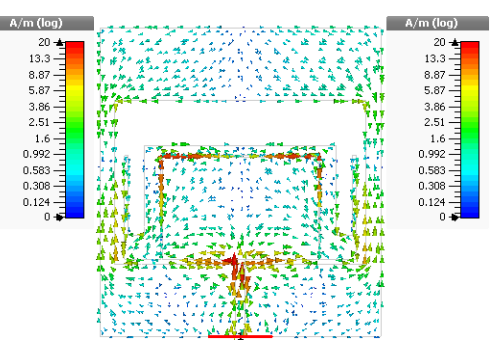

(d)
Fig. 8. Simulated results of current distribution at the operating frequencies of (a) $900 \mathrm{MHz}$, (b) $1800 \mathrm{MHz}$, (c) $2450 \mathrm{MHz}$, and notch frequency of (d) $1437 \mathrm{MHz}$.

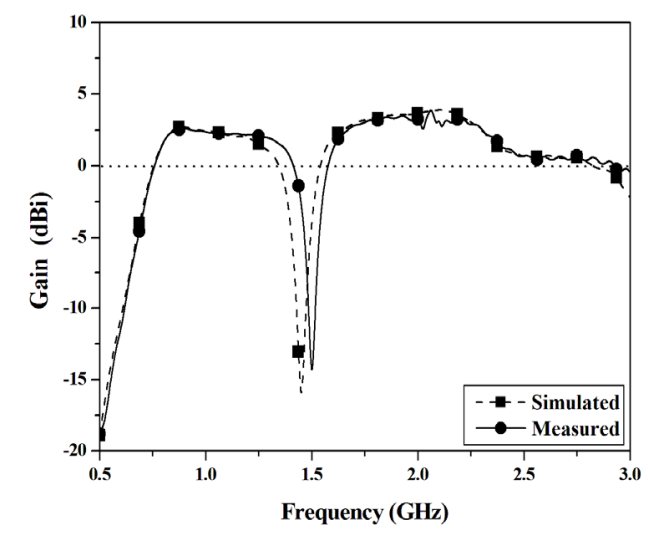

Fig. 9. Simulated and measured total gains of the presented antenna.

stub edge in the horizontal (x-axis) increase as accordingly shown in Figs. 8(b) and 8(c). Moreover, the radiation patterns of the presented antenna are bidirectional at all operating frequencies. 


\section{Conclusion}

The wideband rectangular slot antenna with rectangular stub and folded parasitic line is presented. The antenna creates a frequency rejection band for eliminating the interference frequency resulting from the folded parasitic line. The proposed antenna can operate at the frequency bands of $824-960 \mathrm{MHz}$ and $1710-2485 \mathrm{MHz}$. Furthermore, the radiation patterns of the presented antenna are still bidirectional at the operating frequencies supporting applications of GSM 850, GSM 900, DCS 1800, PCS 1900, UMTS, and WLAN IEEE $802.11 \mathrm{~b} / \mathrm{g}$ systems. The proposed antenna can be applied for mobile repeaters in subway tunnels or corridors.
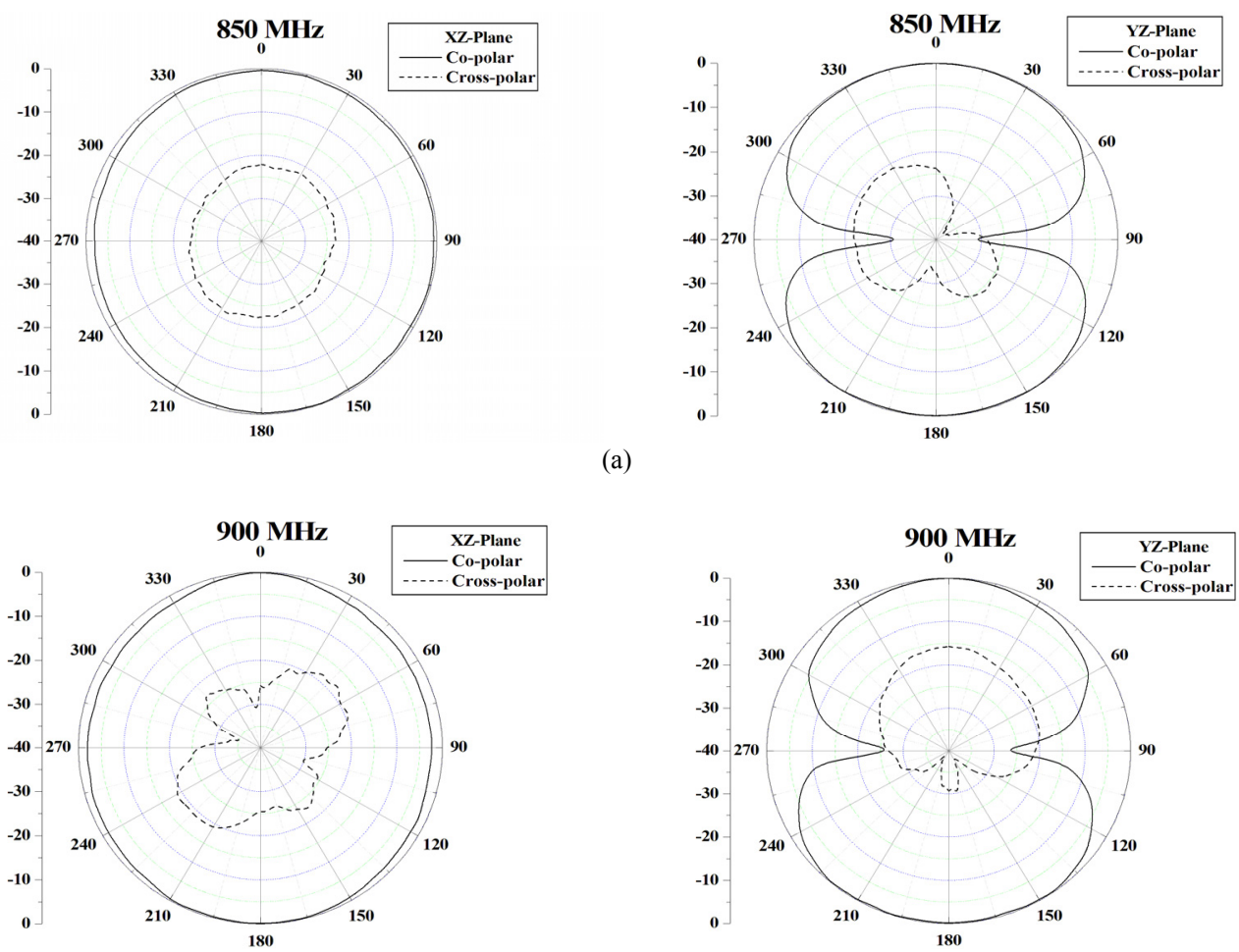

(b)
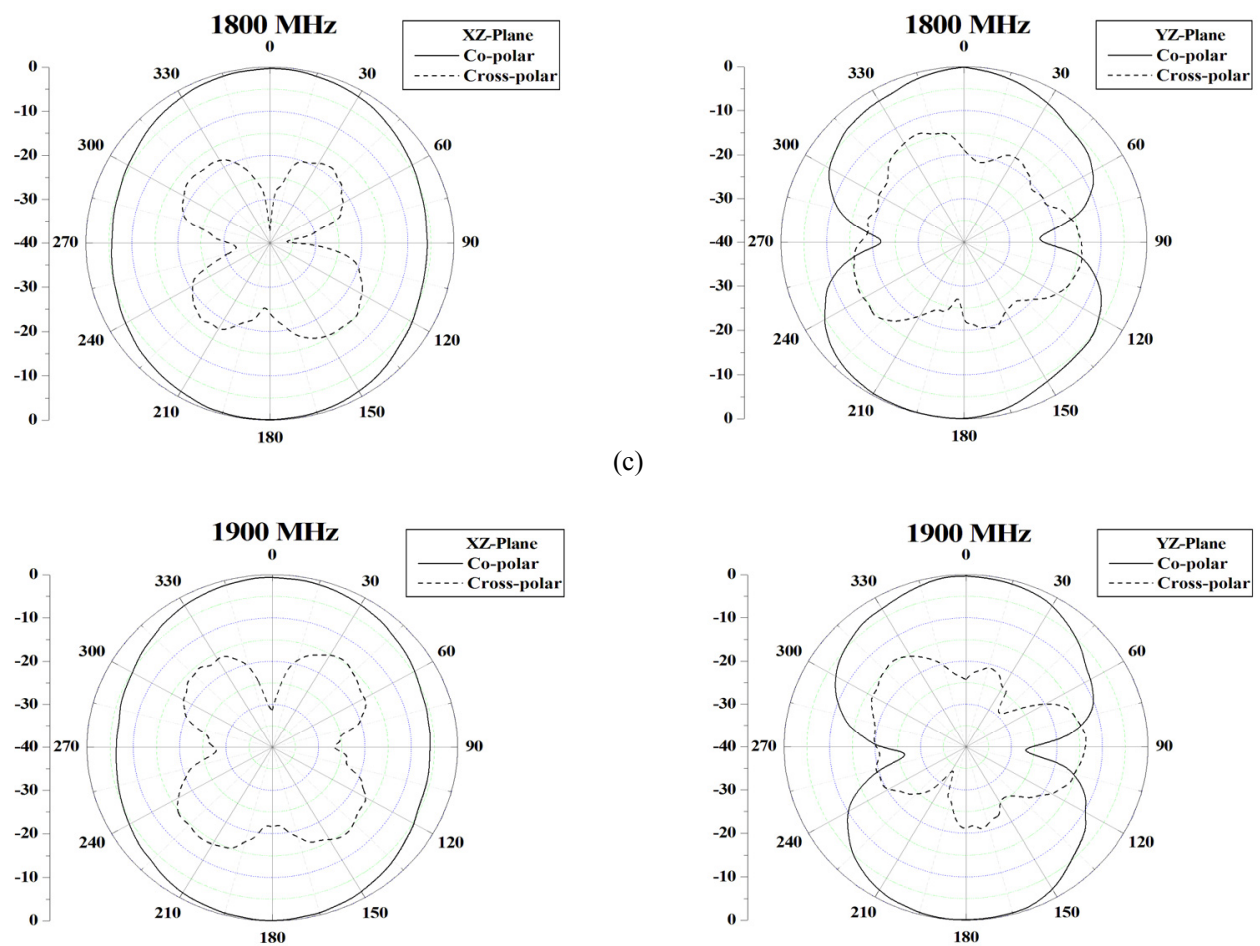

(d) 

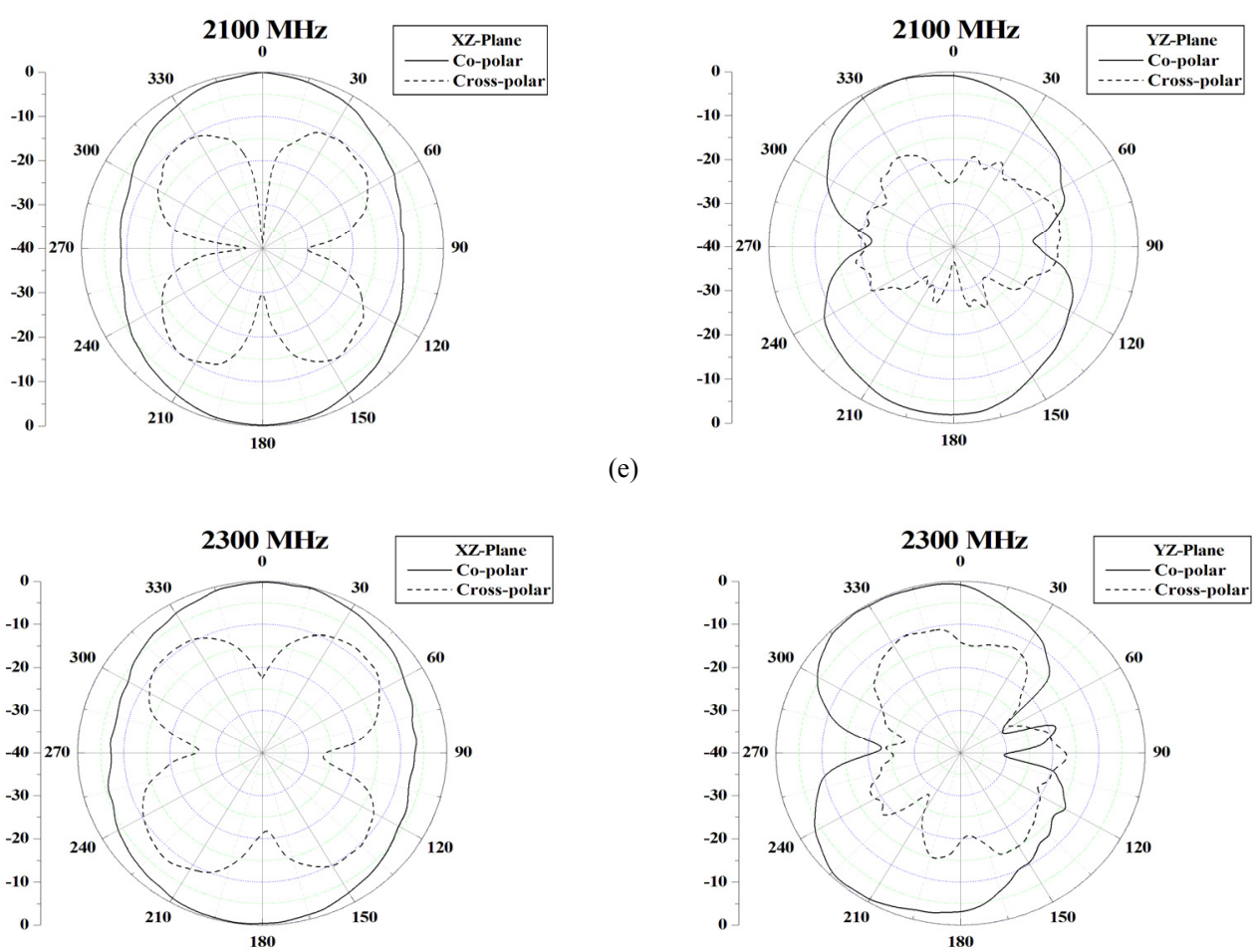

(f)
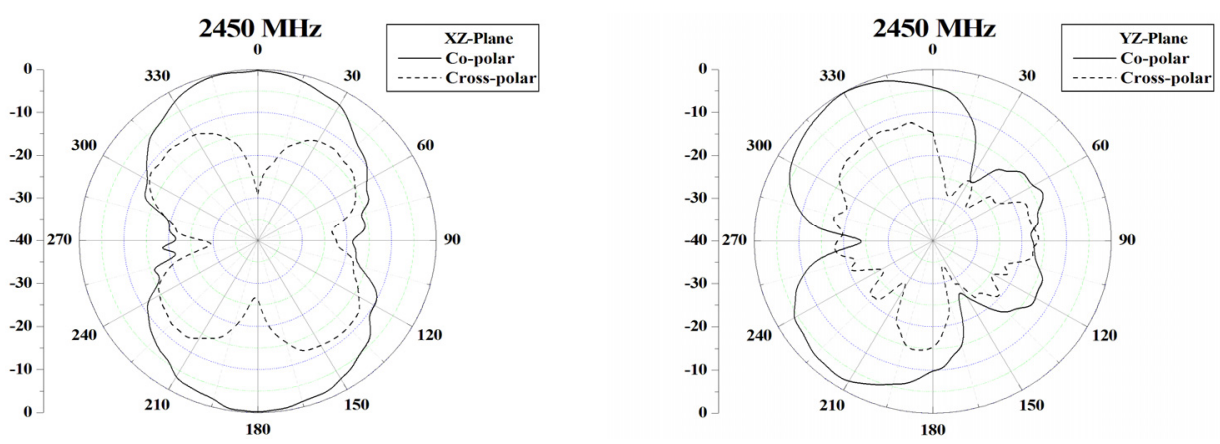

(g)

Fig. 10. Measured radiation patterns of the presented antenna at the frequencies of (a) $850 \mathrm{MHz}$, (b) $900 \mathrm{MHz}$, (c) $1800 \mathrm{MHz}$, (d) $1900 \mathrm{MHz}$, (e) $2100 \mathrm{MHz}$, (f) $2300 \mathrm{MHz}$, and (g) $2450 \mathrm{MHz}$.

\section{Acknowledgments}

This research has been supported by the cooperation of the Thailand Research Fund (TRF) under the grant number RTA-5780010 and King Mongkut's University of Technology North Bangkok.

\section{References}

[1] ZHANG, Z., LI, M. Wireless communication management model of workshop and warehouse manufacturing system. In Proceedings of the $2^{\text {nd }}$ International Conference on Intelligent Computation Technology and Automation ICICTA 2009. Changsha (China), 2009, vol. 4, p. 121-123. DOI: 10.1109/ICICTA.2009.74

[2] WU, K., WU, X. A wireless mobile monitoring system for home healthcare and community medical services. In The $1^{\text {st }}$ International Conference on Bioinformatics and Biomedical
Engineering (iCBBE 2007). China, July 2007, p. 1190-1193. DOI: 10.1109/ICBBE.2007.307

[3] HALl, E. S., VAWDERY, D. K., KNUTSON, C. D., et al. Enabling remote access to personal electronic medical records. IEEE Engineering in Medicine and Biology Magazine, 2003, vol. 22, no. 3, p. 133-139. DOI: 10.1109/MEMB.2003.1213636

[4] JONSSON, M., KUNERT, K. Towards reliable wireless industrial communication with real-time guarantees. IEEE Transactions on Industrial Informatics, 2009, vol. 5, no. 4, p. 429- 442. DOI: 10.1109/TII.2009.2031921

[5] CAO, Y. F., CHEUNG, S. W., YUK, T. I. A multiband slot antenna for GPS/WiMAX/WLAN systems. IEEE Transactions on Antennas and Propagation, 2015, vol. 63, no. 3, p. 952-958. DOI: 10.1109/TAP.2015.2389219

[6] WU, S.-J., KANG, C.-H., CHEN, K.-H., et al. A multiband quasiYagi type antenna. IEEE Transactions on Antennas and Propagation, 2010, vol. 58, no. 2, p. 593-596. DOI: 10.1109/TAP.2010.2041522

[7] ANTONIADES, M. A., ELEFTHERIADES, G. V. A compact multiband monopole antenna with a defected ground plane. IEEE 
Antennas and Wireless Propagation Letters, 2008, vol. 7, p. 652 to 655. DOI: 10.1109/LAWP.2008.2007813

[8] LIU, W.-C. Design of a multiband CPW-fed monopole antenna using a Particle Swarm Optimization approach. IEEE Transactions on Antennas and Propagation, 2005, vol. 53, no. 10, p. 3273 to 3279. DOI: 10.1109 /TAP.2005.856339

[9] LIN, K.-C., LIN, C.-H., LIN, Y.-C. Simple printed multiband antenna with novel parasitic-element design for multistandard mobile phone applications. IEEE Transactions on Antennas and Propagation, 2013, vol. 61, no. 1, p. 488-491. DOI: 10.1109/TAP.2012.2220106

[10] ZHANG, T., LI, R., JIN, G., et al. A novel multiband planar antenna for GSM/UMTS/LTE/Zigbee/RFID mobile devices. IEEE Transactions on Antennas and Propagation, 2011, vol. 59, no. 11, p. 4209-4214. DOI: 10.1109/TAP.2011.216420

[11] MAHATTHANAJATUPHAT, C., WONGSIN, N., AKKARAEKTHALIN, P. A multiband monopole antenna with modified fractal loop parasitic for DCS 1800, WLAN, WiMAX and IMT advanced systems. IEICE Transactions on Communications, 2012, vol. E95B, no. 1, p. 27-33. DOI: 10.1587/transcom.E95.B.27

[12] LI, Y., LI, W., LIU, C., et al. Miniaturization circular wide slot ultra wideband antenna with X-band rejection filter function. In IEEE International Workshop on Antenna Technology (iWAT). Tucson (Arizona, USA), 2012, p. 253-256. DOI: 10.1109/IWAT.2012.6178660

[13] PANDA, J. R., KSHETRIMAYUM, R. S. A compact CPW-fed monopole antenna with a U-shaped slot for $5 \mathrm{GHz} / 6 \mathrm{GHz}$ bandnotched ultrawideband applications. In Workshop on Advanced Antenna Technology, 2010 Indian Antenna Week. Puri (India), 2010, p. 1-4. DOI: $10.1109 /$ AAT.2010.5545942

[14] CHANG, T.-N., WU, M.-C. Band-notched design for UWB antennas. IEEE Antennas and Wireless Propagation Letters, 2008, vol. 7, p. 636-640. DOI: 10.1109/LAWP.2008.2007581

[15] HUANG, C. -Y., HUANG, S. -A., YANG, C. -F. Band-notched ultra-wideband circular slot antenna with inverted $\mathrm{C}$-shaped parasitic strip. Electronics Letters, 2008, vol. 44, no. 15, p. 891-892. DOI: $10.1049 / \mathrm{el}: 20081143$

[16] LUI, W. J., CHENG, C. H., ZHU, H. B. Frequency notched printed slot antenna with parasitic open-circuit stub. Electronics Letters, 2005, vol. 41, no. 20, p. 1094-1095. DOI: 10.1049/el:20052544

\section{About the Authors ...}

Chartree MAHATTHANAJATUPHAT received his B.Eng. degree from King Mongkut's University of Tech- nology North Bangkok (KMUTNB), Thailand, in 2001 and M.Eng. degree from the University of Applied Sciences, Rosenheim, Germany, in 2003. He received the Ph.D. degree from King Mongkut's University of Technology North Bangkok (KMUTNB). His research interests are on the designing of small antennas by using fractal geometry concept and digital signal processing for communication applications.

Narintra SRISOONTORN received the M.Eng. degree in Electrical Engineering from King Mongkut's University of Technology North Bangkok (KMUTNB), Thailand, in 2013. Currently, she is studying for Ph.D. degree at King Mongkut's University of Technology North Bangkok (KMUTNB). Her research interests are wideband and multiband antennas, base station antennas, and mobile wireless applications.

Thanakarn SUANGUN was born in Chiangmai, Thailand. He received the B.Eng. and M.Eng. degrees in Electrical Engineering from King Mongkut's University of Technology North Bangkok (KMUTNB), Thailand, in 2008 and 2010, respectively. Currently, he is studying for Ph.D. degree at King Mongkut's University of Technology North Bangkok (KMUTNB). His research interests are wideband and multiband antennas, and telecommunication applications.

Prayoot AKKARAEKTHALIN was born in Nakorn Pathom, Thailand. He received the B.Eng. and M.Eng. degrees in Electrical Engineering from King the Mongkut's University of Technology North Bangkok (KMUTNB), Thailand, in 1986 and 1990, respectively, and Ph.D. degree from the University of Delaware, Newark,USA, in 1998. From 1986 to 1988, he worked in the Microtek Co.Ltd., Thailand. In 1988, he joined the Dept. of Electrical Engineering at KMUTNB, as instructor. His current research interests include passive and active microwave circuits, wideband and multiband antennas, and telecommunication systems. Dr. Prayoot is a member of IEEE, IEICE Japan, ECTI Thailand and EEAAT Thailand. He was the Chairman for the IEEE MTT/AP/ED Thailand Joint Chapter during 2007 and 2008 and the President of ECTI Association from 2014 to 2015. He is now the head of Senior Research Scholar Project, Thailand Research Fund. 